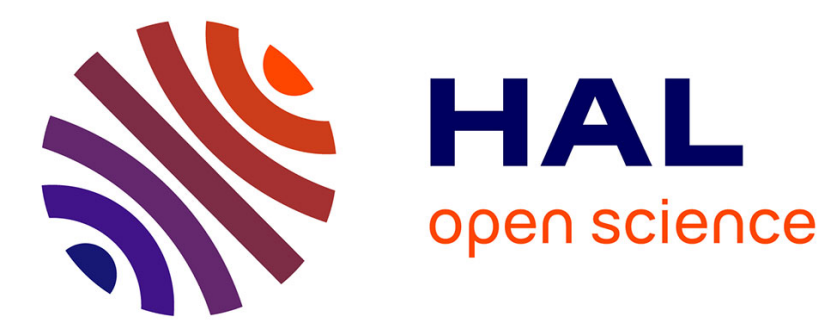

\title{
24. Anomalie à tension nulle dans des jonctions de In-PbTe
}

\author{
V.C. Kieu, R. Granger
}

\section{To cite this version:}

V.C. Kieu, R. Granger. 24. Anomalie à tension nulle dans des jonctions de In-PbTe. Revue de Physique Appliquée, 1970, 5 (6), pp.908-908. 10.1051/rphysap:0197000506090801 . jpa-00243494

\section{HAL Id: jpa-00243494 https://hal.science/jpa-00243494}

Submitted on 1 Jan 1970

HAL is a multi-disciplinary open access archive for the deposit and dissemination of scientific research documents, whether they are published or not. The documents may come from teaching and research institutions in France or abroad, or from public or private research centers.
L'archive ouverte pluridisciplinaire HAL, est destinée au dépôt et à la diffusion de documents scientifiques de niveau recherche, publiés ou non, émanant des établissements d'enseignement et de recherche français ou étrangers, des laboratoires publics ou privés. 


\title{
24. ANOMALIE A TENSION NULLE DANS DES JONCTIONS DE In-PbTe
}

\author{
V. C. KIEU et R. GRANGER
}

Laboratoire de Physique des Solides, C. N. R. S., 92, Bellevue, France

L'anomalie à tension nulle est présentée ainsi que ses variations en fonction du champ magnétique et de la température; elle est due à une mince couche de supraconducteur de température critique $9.5^{\circ} \mathrm{K}$ et de champ critique $20 \mathrm{kOe}$ ayant une bande interdite $\Delta=1.18 \mathrm{meV}$. Des pics apparaissent sur la courbe $\mathrm{d}^{2} I / \mathrm{d} V^{2}(V)$, ceux-ci variant comme l'anomalie à tension nulle avec $T$ et $H$, leur nature est discutée Après avoir passé en revue les différentes possibilités de trouver une couche supraconductrice dans les jonctions $\mathrm{In}-\mathrm{PbTe}$, on est amené à conclure que le supraconducteur incriminé est une couche de tellurure de plomb de forte densité électronique. 